American J. of Engineering and Applied Sciences 3 (1): 31-36, 2010

ISSN 1941-7020

(C) 2010 Science Publications

\title{
Spiral Wound Reverse Osmosis Membranes for the Recovery of Phenol Compounds- Experimental and Parameter Estimation Studies
}

\author{
${ }^{1}$ G. Srinivasan, ${ }^{1}$ S. Sundaramoorthy and ${ }^{2}$ D.V.R. Murthy \\ ${ }^{1}$ Department of Chemical Engineering, Pondicherry Engineering College, Pondicherry, India \\ ${ }^{2}$ Department of Chemical Engineering, National Institute of Technology, Karnataka, Surathkal, India
}

\begin{abstract}
Problem statement: Reverse osmosis is increasingly used as a separation technique in chemical and environmental engineering for the removal of organics and organic pollutants present in waste water. The removal of an organic compound, namely phenol, using a polyamide membrane was investigated in this study. Waste water containing phenol present a serious environmental problem and increasing attention is being given for its removal using RO membranes. Objective of this study is to (i) generate experimental data related to the removal of phenol using a spiral wound polyamide membrane (ii) analyze the performance of the membrane using solution-diffusion model and validate the model with the experimental data. Approach: Experiments were conducted on a laboratory scale spiral wound polyamide RO module. The permeate concentrations and rejection coefficient values were measured for various feed inlet pressures and feed concentrations. The total feed flow rate, $3.33 \times 10^{-4} \mathrm{~m}^{3} \mathrm{sec}^{-1}$ (20 LPM) was not varied. The transport of solvent and solute through the membranes were analyzed using solution-diffusion model taking concentration polarization into account. Results: By varying inlet pressures from $4-14 \mathrm{~kg}_{\mathrm{f}} \mathrm{cm}^{-2}$ ) and feed concentrations of phenol from 200-1100 ppm, the rejection coefficients of the membrane were measured and found to vary from $64-91 \%$. The solvent and solute transport parameters were determined by a graphical procedure using the experimental data and its values were $5.9 \times 10^{-7}\left(\mathrm{~m} \mathrm{~atm}^{-1}\right)$ and $6.54 \times 10^{-7}\left(\mathrm{~m} \mathrm{sec}^{-1}\right)$ respectively. Conclusion: The model and the estimated parameter values were validated with the experimental data. The model was able to predict the rejection within $10 \%$ error. In view of the fact that not much information is available on the usage of spiral wound polyamide RO membrane modules for the removal of phenolic compounds, it may be concluded that the experimental results reported in this study is very significant in the scale up and design of RO system for treatment of industrial effluents containing phenolic compounds.
\end{abstract}

Key words: Reverse osmosis, polyamide membrane, spiral wound module, phenol

\section{INTRODUCTION}

Reverse Osmosis (RO) processes have been widely used for separation and concentration (recovery) of solutes in many fields. The use of RO in the treatment of various effluents of chemical (Bodalo-Santoyo et al., 2003; 2004), petrochemical, electrochemical (Koops et al., 2001), food, paper and tanning industries as well as in the treatment of municipal waste waters have been reported in the literature (Schutte, 2003). Also, the removal of individual contaminants by RO has been studied by very few researchers (Murthy and Gupta, 1999; Moresi et al., 2002; Arsuaga et al., 2006). These individual contaminants, though present at low level can cause problems. The potential of these RO processes to remove organic contaminants was first demonstrated by Chian et al. (1975). A number of studies (Kimura et al., 2003; Xu et al., 2005; Bellona et al., 2004; Yoon and Lueptow, 2006) have been reported on the application of RO for the removal of organics such as endocrine disrupting chemicals, plastic additives, pesticides, pharmaceutically active compounds (PhaC's), benzene and toluene. Typical RO membranes like cellulose acetate and polyamide show very high rejection of above 0.98 for inorganic salts like $\mathrm{NaCl}, \mathrm{Na}_{2} \mathrm{SO}_{4}$. However, for organics, the rejection is reported to be lower and varies widely in the range of 0.3-0.96 (Pozderivic et al., 2006; Senthilmurugan and Gupta, 2006). Phenol and its derivatives are important compounds used extensively in the synthesis of many organic compounds (Senel et al., 2006). Phenolic compounds are found in industrial wastes from coal

Corresponding Author: G. Srinivasan, Department of Chemical Engineering, Pondicherry Engineering College Pondicherry, India 
Am. J. Engg. \& Applied Sci., 3 (1): 31-36, 2010

gas, gas coking, petroleum and pharmaceutical industries as well as in a wide variety of industrial wastes from process involving the use of phenol derivatives resembling those of phenol. In the present investigation, phenol is separated from synthetic aqueous binary solutions using a reverse osmosis thin film composite polyamide membrane and the separation data are analyzed to estimate membrane parameters.

Models that adequately describe the performance of RO membranes play a very significant role in the design of RO processes. Many mechanistic and mathematical models have been proposed to describe RO membranes. Two of the widely used models that describe the transport through the RO membrane are the solution diffusion model proposed by Lonsdale et al. (1965) and the irreversible thermodynamics model proposed by Kedem and Spiegler (1966). These models could be used to predict the solute and solvent transport characteristics of the membranes with reasonable success. In this research, the solution diffusion model will be used. The membrane parameters estimated using the experimental data generated will be utilized in this membrane transport model developed for the theoretical estimation of the rejection capabilities of the membrane.

\section{MATERIALS AND METHODS}

The Perma-TFC polyamide RO membrane in Spiral wound configuration (supplied by Permionics, Vadodara, India) was used in this study. The membrane has an effective area of $0.75 \mathrm{~m}^{2}$ and the module length is 21 " and diameter is 2.5 inches. The membrane is capable of withstanding $\mathrm{pH}$ values in the range of $2-12$, Pressures up to $20 \mathrm{~atm}$ and temperatures up to $50^{\circ} \mathrm{C}$. The flow diagram of the pilot plant unit is shown in Fig. 1.

The experimental RO system consisted of a Polyamide membrane kept inside a stainless steel cylindrical housing capable of withstanding high pressures. A feed tank of $80 \mathrm{~L}$ capacity made of stainless steel is provided for storage and supply of the feed to the system as well as for the collection of the recycled Permeate and Retentate. A high Pressure Pump capable of developing a pressure up to 300 Psi (20 atm) was installed for transporting the feed liquid through the membrane system at a fixed flow rate of 20 LPM. A micron filter installed in the upstream side of the membrane unit prevented entry of suspended solid particles which otherwise would damage the membrane. A manual needle valve was provided at the outlet of the retentate line to pressurize the feed liquid to a desired pressure indicated by pressure gauges installed in both the feed and retentate lines.

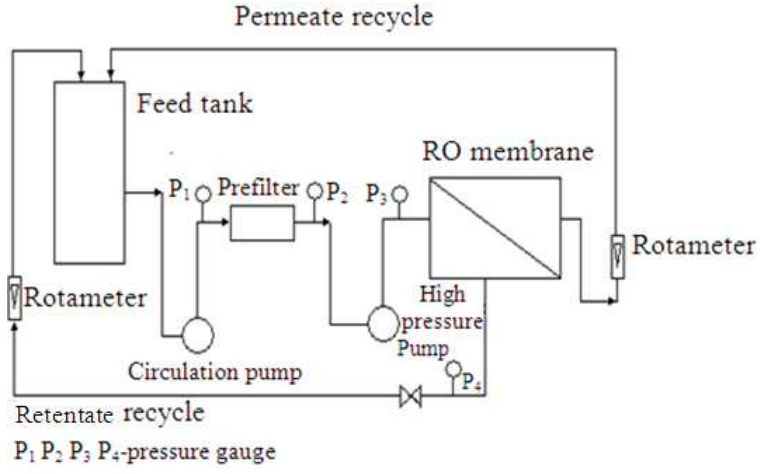

Fig. 1: Flow diagram of the pilot plant membrane unit

The permeate and the concentrate flow rates were measured by means of two glass rotameters containing metal floats. Since the feed gets heated by the high pressure pump, it was necessary to cool the feed reservoir by circulating cooling water through a cooling coil in the feed tank to keep the temperature at $35 \pm 2^{\circ} \mathrm{C}$.

Solutions were prepared by dissolving definite quantities (in ppm) of pure phenol (>99.5\% purity) in raw water in the feed tank of 80 liters capacity. The flow rate of the feed solution was set constant at $3.33 \times 10^{-4} \mathrm{~m}^{3} \mathrm{sec}^{-1}$ (20 LPM. Operation was in a recycle mode, i.e., the feed-reject solution as well as permeate were recycled to the feed tank (closed loop). Samples of feed, permeate and retentate were taken at regular intervals during the run and the unit was operated for sufficient time to ensure steady state conditions. The concentrations of feed, permeate and retentate samples were analyzed using HPLC (Make: Perkin Elmer, USA) equipped with an UV detector and C-18 column. The mobile phase used was Acetonitrilewater $(50: 50 \%)$ delivered at a constant flow rate of

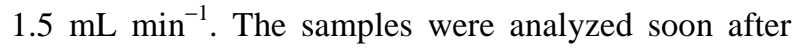
collection. A set of three samples were collected at a time and checked for consistency. The experiments were carried out using binary mixtures containing phenol compound in water of varying solute concentration in the range of $2.125 \times 10^{-3}$ $10.6 \times 10^{-3} \mathrm{Kmol} \mathrm{m}^{-3}$ (200-1100 ppm) and the feed inlet pressure in the range of $4-15 \mathrm{~kg}_{\mathrm{f}} \mathrm{cm}^{-2}$. The membrane system was first run with raw water to determine the solvent (water) transport parameter. Experiments are repeated for different feed concentrations of phenol. A total of 29 sets of readings obtained from these experiments are given in Table 1.

Theory: The solution diffusion model with concentration polarization is used for solute and solvent transport through the membrane. 
Am. J. Engg. \& Applied Sci., 3 (1): 31-36, 2010

Table 1: Experimental data obtained for rejection of phenol for feed flow rate $F_{i}=3.33 \times 10^{-4} \mathrm{~m}^{3} \mathrm{sec}^{-1}$

\begin{tabular}{|c|c|c|c|c|c|c|c|c|c|}
\hline $\begin{array}{l}\text { Sr. } \\
\text { No. }\end{array}$ & $\begin{array}{l}\mathrm{C}_{\mathrm{i} \times 10^{3}} \\
\left(\mathrm{kmol} \mathrm{m}^{-3}\right)\end{array}$ & $\begin{array}{l}\mathrm{P}_{\mathrm{i}} \\
\text { (atm) }\end{array}$ & $\begin{array}{l}\mathrm{P}_{\mathrm{o}} \\
\text { (atm) }\end{array}$ & $\begin{array}{l}\mathrm{T} \\
\left({ }^{\circ} \mathrm{C}\right)\end{array}$ & $\begin{array}{l}\mathrm{C}_{\mathrm{p}} \times 10^{3} \\
\left(\mathrm{Kmol} \mathrm{m}^{-3}\right)\end{array}$ & $\begin{array}{l}\mathrm{C}_{0} \times 10^{3} \\
\left(\mathrm{Kmol} \mathrm{m}^{-3}\right)\end{array}$ & $\begin{array}{l}\mathrm{F}_{\mathrm{p}} \times 10^{6} \\
\left(\mathrm{~m}^{3} \sec ^{-1}\right)\end{array}$ & $\begin{array}{l}F_{0} \times 10^{4} \\
\left(\mathrm{~m}^{3} \sec ^{-1}\right)\end{array}$ & $\mathrm{R}$ \\
\hline 1 & 2.125 & 4.93 & 2.99 & 32.5 & 0.831 & 2.35 & 3.53 & 3.30 & 0.6462 \\
\hline 2 & 2.125 & 6.90 & 4.96 & 33.1 & 0.647 & 2.37 & 5.20 & 3.30 & 0.7270 \\
\hline 3 & 2.125 & 8.90 & 6.90 & 33.0 & 0.580 & 2.41 & 7.20 & 3.20 & 0.7593 \\
\hline 4 & 2.125 & 10.90 & 8.90 & 33.2 & 0.524 & 2.45 & 9.60 & 3.16 & 0.7861 \\
\hline 5 & 2.125 & 14.80 & 12.90 & 34.0 & 0.349 & 2.78 & 12.20 & 3.06 & 0.8745 \\
\hline 6 & 4.250 & 4.93 & 2.99 & 32.2 & 1.240 & 5.30 & 3.30 & 3.33 & 0.7660 \\
\hline 7 & 4.250 & 6.90 & 4.96 & 32.8 & 1.050 & 5.62 & 5.00 & 3.30 & 0.8132 \\
\hline 8 & 4.250 & 8.90 & 6.90 & 33.5 & 0.600 & 5.60 & 7.00 & 3.25 & 0.8929 \\
\hline 9 & 4.250 & 10.90 & 8.90 & 33.9 & 0.720 & 5.70 & 8.50 & 3.16 & 0.8737 \\
\hline 10 & 4.250 & 12.80 & 10.90 & 34.5 & 0.685 & 5.74 & 10.25 & 3.00 & 0.8807 \\
\hline 11 & 4.250 & 14.80 & 10.90 & 34.5 & 0.718 & 5.82 & 12.25 & 3.08 & 0.8766 \\
\hline 12 & 6.375 & 4.93 & 2.99 & 32.5 & 1.400 & 6.94 & 3.20 & 3.33 & 0.7983 \\
\hline 13 & 6.375 & 6.90 & 4.96 & 33.0 & 1.240 & 6.95 & 4.33 & 3.25 & 0.8216 \\
\hline 14 & 6.375 & 8.90 & 6.90 & 33.2 & 1.176 & 7.11 & 5.93 & 3.20 & 0.8346 \\
\hline 15 & 6.375 & 10.90 & 8.90 & 33.5 & 0.940 & 7.12 & 7.00 & 3.16 & 0.8680 \\
\hline 16 & 6.375 & 12.80 & 10.90 & 33.8 & 0.870 & 7.24 & 8.70 & 3.08 & 0.8798 \\
\hline 17 & 6.375 & 14.80 & 12.90 & 34.0 & 0.630 & 7.33 & 11.10 & 3.00 & 0.9141 \\
\hline 18 & 8.500 & 4.93 & 2.99 & 32.0 & 2.610 & 8.88 & 3.13 & 3.20 & 0.7061 \\
\hline 19 & 8.500 & 6.90 & 4.96 & 32.5 & 2.220 & 8.88 & 4.53 & 3.16 & 0.7500 \\
\hline 20 & 8.500 & 8.90 & 6.90 & 32.8 & 1.930 & 8.91 & 6.20 & 3.13 & 0.7834 \\
\hline 21 & 8.500 & 10.90 & 8.90 & 33.0 & 1.600 & 9.20 & 8.20 & 3.08 & 0.8261 \\
\hline 22 & 8.500 & 12.80 & 10.90 & 33.2 & 1.470 & 9.20 & 9.30 & 3.03 & 0.8402 \\
\hline 23 & 8.500 & 14.80 & 12.90 & 33.5 & 1.400 & 9.30 & 11.50 & 3.00 & 0.8495 \\
\hline 24 & 10.600 & 4.93 & 2.99 & 31.5 & 3.090 & 10.70 & 2.66 & 3.25 & 0.7112 \\
\hline 25 & 10.600 & 6.90 & 4.96 & 32.2 & 2.520 & 10.71 & 4.13 & 3.16 & 0.7647 \\
\hline 26 & 10.600 & 8.90 & 6.90 & 32.6 & 2.020 & 11.00 & 5.86 & 3.13 & 0.8164 \\
\hline 27 & 10.600 & 10.90 & 8.90 & 32.8 & 1.830 & 11.10 & 7.50 & 3.08 & 0.8351 \\
\hline 28 & 10.600 & 12.80 & 10.90 & 32.8 & 1.690 & 10.99 & 9.00 & 3.00 & 0.8462 \\
\hline 29 & 10.600 & 14.80 & 12.90 & 33.0 & 1.400 & 11.10 & 10.50 & 2.91 & 0.8739 \\
\hline
\end{tabular}

Completely mixed flow pattern is assumed on both the retentate and permeate sides. The pressure on the retentate side of the membrane is taken as the average of feed inlet and outlet pressure. Atmospheric pressure is assumed on the permeate side:

$\Delta \mathrm{P}=\left[\left(\mathrm{P}_{\mathrm{i}}+\mathrm{P}_{\mathrm{o}}\right) / 2\right]-\mathrm{P}_{\mathrm{p}}$

The working equations of solution diffusion model (Mason and Lonsdale, 1990; Gupta, 1985) are:

$$
\begin{aligned}
& \mathrm{J}_{\mathrm{s}}=\left(\mathrm{B}_{\mathrm{s}}\right)\left(\mathrm{C}_{\mathrm{w}}-\mathrm{C}_{\mathrm{P}}\right) \\
& \mathrm{J}_{\mathrm{b}}=\mathrm{A}_{\mathrm{W}}(\Delta \mathrm{P}-\Delta \Pi) \\
& \mathrm{J}_{\mathrm{S}}=\mathrm{J}_{\mathrm{b}} \mathrm{C}_{\mathrm{P}}
\end{aligned}
$$

Where:

$\mathrm{J}_{\mathrm{s}} \quad=$ The solute flux $\left(\mathrm{Kmol} \mathrm{m}^{-2} \mathrm{sec}\right)$

$\mathrm{J}_{\mathrm{b}}=$ Solvent flux $\left(\mathrm{m}^{3} \mathrm{sec}^{-1} \mathrm{~m}^{2}\right)=\mathrm{m} \mathrm{sec}^{-1}$

$\mathrm{A}_{\mathrm{w}}=$ The solvent transport parameter ( $\mathrm{m} \mathrm{sec}^{-1}$.atm)

$\mathrm{B}_{\mathrm{s}}=$ The solute transport parameter in $\mathrm{m} \mathrm{sec}^{-1}$

$\Delta \mathrm{P}=$ The pressure difference across the membrane (transmembrane pressure)
$\Delta \Pi=$ The osmotic pressure difference across the membrane

The Osmotic pressure may be linearly related to Concentration $(\mathrm{C})$ by the equation:

$\Pi(\mathrm{C})=\mathrm{RTC}$

If:

$\mathrm{C}_{\mathrm{w}}=$ The concentration at the membrane feed side $\mathrm{C}_{\mathrm{p}}=$ The concentration at the permeate side, then

$\Delta \Pi=\Pi\left(\mathrm{C}_{\mathrm{w}}\right)-\Pi\left(\mathrm{C}_{\mathrm{p}}\right)$

Intrinsic rejection coefficient:

$\mathrm{R}^{\mathrm{o}}=1-\left(\frac{\mathrm{C}_{\mathrm{P}}}{\mathrm{C}_{\mathrm{w}}}\right)$

Rejection coefficient:

$R=1-\left(\frac{C_{P}}{C_{O}}\right)$ 
$\operatorname{Recovery} \theta=\left(\frac{F_{P}}{F_{i}}\right)$

and

Separation coefficient $=\alpha=\left(\frac{\mathrm{A}_{\mathrm{w}}}{\mathrm{B}_{\mathrm{s}}}\right)$

$\mathrm{M}=\mathrm{C}_{\mathrm{w}} / \mathrm{C}_{\mathrm{o}}$

Accumulation of the impermeable solutes on the membrane surface leads to the development of a concentration polarization layer which may be determined by the concentration polarization model given by:

$e^{\left(\frac{J_{b}}{k}\right)}=\frac{C_{w}-C_{p}}{C_{b}-C_{p}}$

Here:

$\mathrm{C}_{\mathrm{b}}=$ The concentration of solute in the bulk solution

$\mathrm{k}=$ The mass transfer coefficient which is estimated using the correlation as reported by Wankat (1990):

$\mathrm{k}=1.177\left(\frac{\mathrm{U}_{\mathrm{b}} \mathrm{D}^{2}}{\mathrm{hL}}\right)^{1 / 3}$

Where:

$\mathrm{D}=$ The diffusivity of the solute

$\mathrm{U}_{\mathrm{b}}=$ The bulk velocity of the solution

$\mathrm{h}=$ The spacing between the plates

Substitution of Eq. 6, 7 and 10 in Eq. 11 gives the following relationship:

$$
\frac{\mathrm{J}_{\mathrm{b}}}{\mathrm{e}^{\frac{\mathrm{b}}{\mathrm{k}}}}=\mathrm{B}_{\mathrm{s}}\left[\frac{\mathrm{R}}{1-\mathrm{R}}\right]
$$

Using the experimental values of $\mathrm{J}_{\mathrm{b}}$ and $\mathrm{R}$, a plot of $\frac{J_{b}}{e^{\frac{b}{k}}}$ Vs $\frac{R}{1-R}$ is made to estimate the solute transport parameter $\left(\mathrm{B}_{\mathrm{S}}\right)$ for both phenol-water and chlorophenol-water solutions. The other membrane parameter, i.e., the solvent transport parameter $\left(\mathrm{A}_{\mathrm{W}}\right)$ can be found out from a plot of $\mathrm{J}_{\mathrm{b}} \mathrm{Vs}(\Delta \mathrm{P}-\Delta \Pi)$. The values of $A_{w}, B_{S}$ and $k$ were substituted in the theoretical model described earlier and the values of Rejection coefficient $\mathrm{R}$, Permeate concentration $\mathrm{C}_{\mathrm{P}}$ and flow rates were determined theoretically.

\section{RESULTS AND DISCUSSION}

The experimental separation data's obtained for Phenol-water are presented in Fig. 2 and 3, where the observed Rejection coefficient (R) and the permeate concentration are plotted against the inlet pressure, $\mathrm{Pi}$ for different feed concentrations. The rejection capabilities of the membrane for phenol are shown in the Fig. 2, where the measured rejection coefficient was plotted against the applied pressure across the membranes. It was found that the value of $\mathrm{R}$ increases with the increasing applied pressure. The maximum rejection obtained is around $90 \%$ for phenol. Figure 3 shows the variation of permeate concentration with inlet pressure for various feed concentration of phenol.

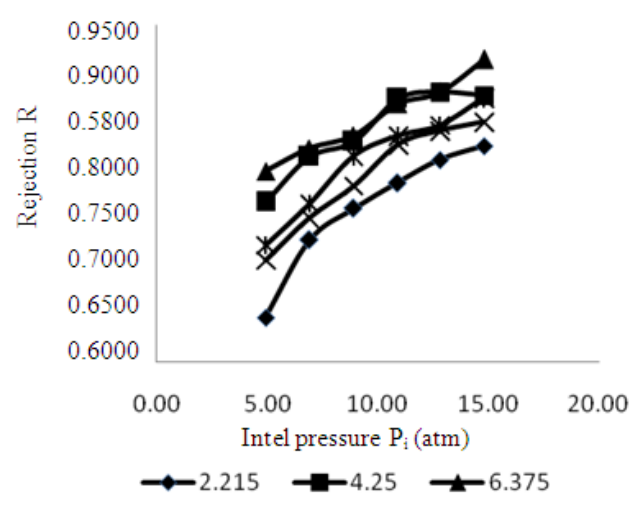

Fig. 2: Rejection Vs Inlet pressure for feed concentrations, $\mathrm{C}_{\mathrm{i}} \times 10^{3}\left(\mathrm{kmol} \mathrm{m}^{-3}\right)$ of phenol

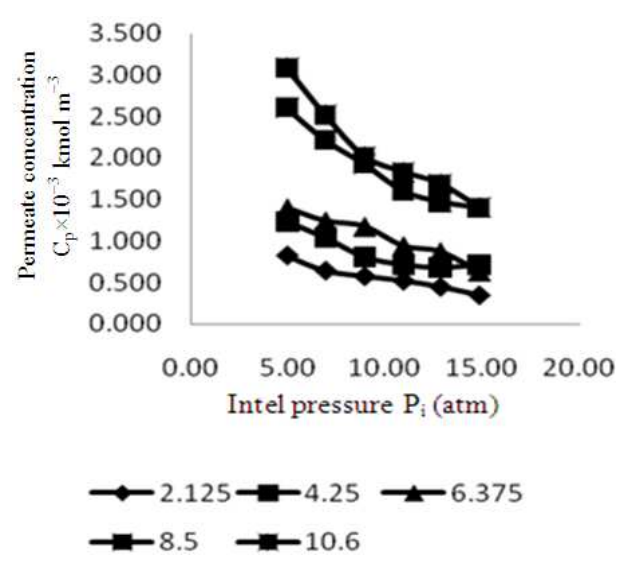

Fig. 3: Permeate concentration Vs Inlet pressure at various feed concentrations $\mathrm{C}_{\mathrm{i}} \times 10^{3}\left(\mathrm{kmol} \mathrm{m}^{-3}\right)$ of phenol 
Am. J. Engg. \& Applied Sci., 3 (1): 31-36, 2010
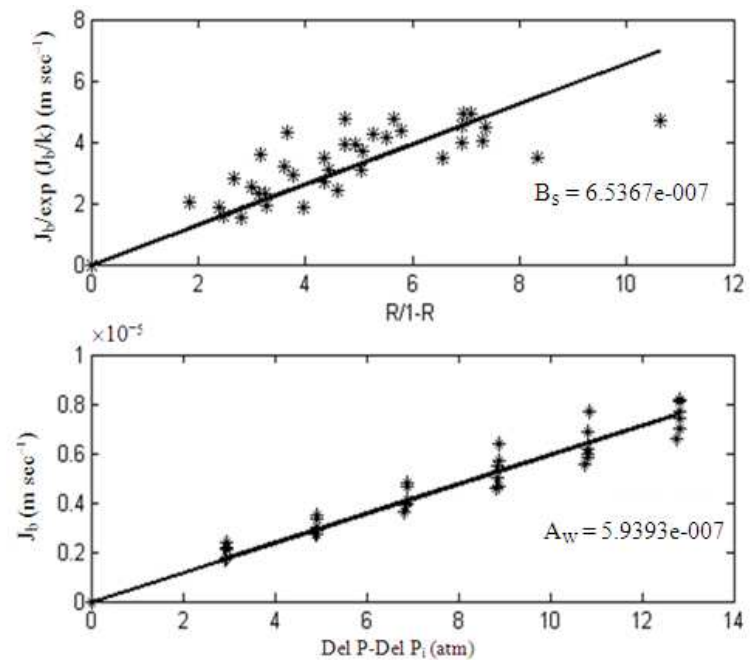

Fig. 4: Graphical plots for the estimation of parameters $\mathrm{A}_{\mathrm{w}}$ and $\mathrm{B}_{\mathrm{s}}$

Table 2: Experimental and theoretical data showing rejection characteristics for phenol separation

\begin{tabular}{llrllr}
\multicolumn{5}{c}{ characteristics for phenol separation } \\
\hline Sr. No. & $\begin{array}{l}\mathrm{C}_{\mathrm{i} \times 10^{3}} \\
\left(\mathrm{kmol} \mathrm{m}^{-3}\right)\end{array}$ & $\begin{array}{c}\mathrm{P}_{\mathrm{i}} \\
(\mathrm{atm})\end{array}$ & $\mathrm{R}(\mathrm{exp})$ & $\mathrm{R}$ (theory) & Error $(\%)$ \\
\hline 1 & 2.125 & 6.93 & 0.646 & 0.642 & 0.59 \\
2 & 2.125 & 8.90 & 0.727 & 0.698 & 4.00 \\
3 & 2.125 & 10.90 & 0.759 & 0.733 & 3.45 \\
4 & 2.125 & 12.90 & 0.786 & 0.758 & 3.62 \\
5 & 2.125 & 16.80 & 0.874 & 0.790 & 9.70 \\
6 & 4.250 & 6.93 & 0.766 & 0.680 & 11.23 \\
7 & 4.250 & 8.90 & 0.813 & 0.737 & 9.38 \\
8 & 4.250 & 10.90 & 0.893 & 0.772 & 13.53 \\
9 & 4.250 & 12.90 & 0.874 & 0.796 & 8.88 \\
10 & 4.250 & 14.80 & 0.881 & 0.813 & 7.67 \\
11 & 4.250 & 14.80 & 0.877 & 0.813 & 7.25 \\
12 & 6.375 & 6.93 & 0.798 & 0.696 & 12.83 \\
13 & 6.375 & 8.90 & 0.822 & 0.754 & 8.21 \\
14 & 6.375 & 10.90 & 0.835 & 0.790 & 5.39 \\
15 & 6.375 & 12.90 & 0.868 & 0.814 & 6.27 \\
16 & 6.375 & 14.80 & 0.880 & 0.830 & 5.63 \\
17 & 6.375 & 16.80 & 0.914 & 0.844 & 7.68 \\
18 & 8.500 & 6.93 & 0.706 & 0.704 & 0.30 \\
19 & 8.500 & 8.90 & 0.750 & 0.764 & -1.83 \\
20 & 8.500 & 10.90 & 0.783 & 0.800 & -2.08 \\
21 & 8.500 & 12.90 & 0.826 & 0.824 & 0.28 \\
22 & 8.500 & 14.80 & 0.840 & 0.840 & -0.03 \\
23 & 8.500 & 16.80 & 0.849 & 0.854 & -0.52 \\
24 & 10.600 & 6.93 & 0.711 & 0.708 & 0.42 \\
25 & 10.600 & 8.90 & 0.765 & 0.770 & -0.63 \\
26 & 10.600 & 10.90 & 0.816 & 0.806 & 1.26 \\
27 & 10.600 & 12.90 & 0.835 & 0.830 & 0.57 \\
28 & 10.600 & 14.80 & 0.846 & 0.847 & -0.11 \\
29 & 10.600 & 16.80 & 0.874 & 0.861 & 1.52 \\
\hline & & & & &
\end{tabular}

The permeate concentration decreases steeply with increase in inlet pressure. Also, it may be found that for a particular inlet pressure, the permeate concentration increases with increase in feed concentration. It is evident from the Table 1 that permeate flux is seen to be decreasing with increasing feed concentration. This is because the osmotic pressure increases with increasing feed concentration and this reduces the driving force for the mass transfer, thus leading to lower permeate flux. Also, since the driving force for the mass transfer increases for higher feed pressures, the permeate flux is seen to increase with increasing applied pressures.

Experimental data obtained from the pilot plant RO spiral wound module for various operating conditions were used to obtain parameters of these systems using our parameter estimation program. The value of mass transfer coefficient ' $\mathrm{k}$ ' using the correlation given in equation 13 is $12.230 \times 10^{-6} \mathrm{~m} \mathrm{sec}^{-1}$. The solvent transport coefficient $\left(\mathrm{A}_{\mathrm{W}}\right)$ was determined by using the pure water permeability data and were also verified with a plot shown in Fig. 4 and its value is found to be constant for all cases i.e., $5.9 \times 10^{-7}\left(\mathrm{~m} \mathrm{~atm}^{-1}\right)$. The value of solute transport $\left(\mathrm{B}_{\mathrm{s}}\right)$ parameter is found to be $6.54 \times 10^{-7}\left(\mathrm{~m} \mathrm{sec}^{-1}\right)$ for phenol as obtained from Fig. 4. These estimated parameters were used for the prediction of separation data as shown in Table 2 and compared with the experimental values obtained earlier (Table 1). The model is able to predict the rejection within error of $10 \%$.

\section{CONCLUSION}

The research reported in this study dealt with product recovery and concentration reduction of pollutants in industrial wastewater using a RO spiral wound membrane. The pollutant investigated was phenol. The membrane was operated in a continuous steady state mode and the experimental data were obtained for the removal of phenol for a wide range of solute concentration and feed inlet pressures. The solution diffusion model with concentration polarization was used for solute and solvent transport through the membrane. Completely mixed flow pattern was assumed on both the retentate and permeate sides. The model was tested for its consistency and validated with the experiment data obtained for phenol. Also, the solute and solvent transport parameters of the membrane for phenol were estimated and used to predict the separation data. These predicted data were then compared with the experimental values and the percentage error was calculated.

\section{REFERENCES}

Arsuaga, J.M., M.J. Lopez-Munoz, A. Sotto and G. del Rosario, 2006. Retention of phenols and carboxylic acids by nanofiltration/reverse osmosis membranes: Sieving and membrane solute interaction effects. Desalination, 731-733. DOI: 10.1016/J.DESAL.2006.03.502 
Bellona, C., J.E. Drewes, P. Xua and G. Amy, 2004. Factors affecting the rejection of organic solutes during NF/RO treatment-a literature review. Water Res., 38: 2795-2809. DOI: 10.1016/J.WATRES.2004.03.034

Bodalo-Santoyo, A., J.L. Gomez-Carrasco, E. Gomez-Gomez, F. Maximo-Martin and A.M. Hidalgo-Montesinos, 2003. Application of reverse osmosis membrane to reduce pollutants present in industrial waste water. Desalination, 155: 101-108. DOI: 10.1016/S00119164(03)00287-X

Bodalo-Santoyo, A., J.L. Gomez-Carrasco, E. Gomez-Gomez, M.F. Maximo-Martin and A.M. Hidalgo-Montesinos, 2004. Spiral wound membrane reverse osmosis and the treatment of industrial effluents. Desalination, 160: 151-158. DOI: 10.1016/S00119164(04)90005-7

Chian, E.S.K., W.N. Bruce and H.H.P. Fang, 1975. Removal of pesticides by reverse osmosis. Environ. Sci. Technol., 9: 52-59. DOI: 10.1021/es60099a009

Gupta, S.K., 1985. Analytical Design Equations for reverse osmosis systems, industrial engineering chemical process design. Ind. Eng. Chem. Process Des. Dev., 24: 1240-1248. DOI: 10.1021/i200031a057

Kedem, O. and K.S. Spiegler, 1966. Thermodynamics of hyperfiltration (reverse osmosis): Criteria for efficient membranes. Desalination, 1: 311-326. DOI: 10.1016/S0011-9164(00)80018-1

Kimura, K., G. Amy, J.E. Drewes, T. Heberer, T.U. Kim and Y. Watanabe, 2003. Rejection of organic micro pollutants (disinfection by-products, endocrine disrupting compounds and pharmaceutically active compounds) by NF/RO membranes. J. Membr. Sci., 227: 113-121. http://cat.inist.fr/?aModele $=$ afficheN\&cpsidt $=1530$ 9944

Koops, G.H., S. Yamada and S.I. Nakao, 2001. Separation of linear hydrocarbons and carboxylic acids from ethanol and hexane solutions by reverse osmosis. J. Membr. Sci., 189: 241-254. DOI: 10.1016/S0376-7388(01)00404-5

Lonsdale, H.K., U. Merten and R.L. Riley, 1965. Transport properties of cellulose acetate osmotic membranes. J. Polymer Sci., 9: 1341-1362. DOI: 10.1002/app.1965.070090413

Mason, E.A. and H.K. Lonsdale, 1990. Statistical mechanical theory of membrane transport. J. Membr. Sci., 51: 1-81. DOI: 10.1016/S03767388(00)80894-7
Moresi, M., B. Ceccantoni and S. Lo Presti, 2002. Modeling of ammonium fumarate recovery from model solutions by nanofiltration and reverse osmosis. J. Membr. Sci., 209: 405-420. http://cat.inist.fr/?aModele $=$ afficheN\&cpsidt $=1397$ 6675

Murthy, Z.V.P. and S.K. Gupta, 1999. Sodium cyanide separation and parameter estimation for reverse osmosis thin film composite polyamide membrane. J. Membr. Sci., 154: 89-103. DOI: 10.1016/S03767388(98)00280-4

Pozderivic, A., T. Moslavac and A. Pichler, 2006. Concentration of aqueous solutions of organic components by reverse osmosis II. Influence of transmembrane pressure and membranetype on concentration of different alcohol solutions by reverse osmosis. J. Food Eng., 77: 810-817. http://cat.inist.fr/?aModele $=$ afficheN\&cpsidt $=1796$ 1584

Schutte, F.C., 2003. The rejection of specific organic compounds by reverse osmosis membranes. Desalination, 158: 285-294. DOI: 10.1016/S00119164(03)00466-1

Senel, S., A. Kara, G. Alsaneak and A. Denizli, 2006. Removal of phenol and chlorophenols from water with reusable dye-affinity hollow fibers. J. Hazard. Mater., 138: 317-324. http://cat.inist.fr/?aModele $=$ afficheN\&cpsidt $=1839$ 5813

Senthilmurugan, S. and S.K. Gupta, 2006. Separation of inorganic and organic compounds by using a radial flow hollow fiber reverse module. Desalination, 196: 221-236. DOI: 10.1016/J.DESAL.2006.02.001

Wankat, P.C., 1990. Rate-Controlled Separations. 1st Edn., Springer, ISBN: 10: 1851665218, pp: 873.

Xu, P., J.E. Drewes, C. Bellona, G. Amy and T.U. Kim et al., 2005. Rejection of Emerging Organic micro pollutants in nanofiltration-reverse osmosis membrane applications. Water Environ. Res., 77: 40-48. http://cat.inist.fr/?aModele $=$ afficheN\&cpsidt $=1709$ 2748

Yoon, Y. and R.M. Lueptow, 2006. Removal of organic contaminants by RO and NF members. J. Membr. Sci., 261: 76-86. http://www.ce.sc.edu/DeptInfo/Members/Faculty/y oon.html 